\title{
COMPARATIVE ANALYSIS OF APPLICATION OF CONVENTIONAL COLONOSCOPY AND NBI COLONOSCOPY FOR DETECTION OF EARLY COLORECTAL CANCER
}

\author{
Anton Tonev ${ }^{1}$, Nikola Kolev', Valentin Ignatov ${ }^{1}$, Georgi Ivanov', Vilian Platikanov ${ }^{2}$, \\ Aleksandar Zlatarov ${ }^{1}$, Krasimir Ivanov ${ }^{1}$ \\ ${ }^{1}$ First Clinic of Surgery and ${ }^{2}$ Department of Anesthesiology and Intensive Care, \\ St. Marina University Hospital of Varna
}

\begin{abstract}
PURPOSE: Extending life expectancy is one of the major causes for increasing cancer incidence rate. The objective of the present investigation is to compare the diagnostic value of conventional and narrow band imaging (NBI) colonoscopy for the early diagnosis of colorectal cancer.

MATERIAL AND METHODS: We examined 163 patients hospitalized in the First Clinic of Surgery, St. Marina University Hospital of Varna, for a period from 2010 to 2012 and compared the diagnostic modalities of conventional colonoscopy and NBI-colonoscopy.

RESULTS: NBI colonoscopy with magnifying endoscopy had the potential to detect more lesions remaining not identified by conventional endoscopy. The relative share of newly-increased mucosal changes increased by 1,9 times (52\%). The newly-diagnosed lesions were mostly small sized. We diagnosed by 2,7 times more lesions sized less than one $\mathrm{mm}$ as well as by two times, 1,7 and 1,3 times more lesions sized 1-3 mm, 3-5 mm and 5-9 $\mathrm{mm}$, respectively. The method did not establish any new formations larger than one $\mathrm{cm}$ or more. The main part of the newly-detected lesions presented with non-specific inflammatory changes, i. e. by 9,2 times more often when compared to conventional endoscopy and represented hyperplastic/inflammatory polyps by 2-3 times more often. In four new lesions there were either an early cancer, or areas of high-grade dysplasia while in 12 ones there was a low-grade dysplasia.
\end{abstract}

CONCLUSION: NBI colonoscopy with magnifying endoscopy represents a reliable method for the diagnosis of small neoplasms of the colon.

Key words: conventional colonoscopy, NBI colonoscopy, colorectal cancer, diagnosis, histopathology

Address for correspondence:

Anton Tonev, MD, PhD

First Clinic of Surgery,

St. Marina University Hospital of Varna

1 Hristo Smirnenski Str., 9010 Varna, Bulgaria

e-mail:teraton@abv.bg

Received: October 01, 2012

Accepted: March 03, 2013

\section{INTRODUCTION}

The incidence rate of cancer of the colon and rectum increases with age. The incidence rate of colorectal cancer (CRC) per 100,000 individuals aged 80 years was by seven times higher than that of those aged 50-54 years (13). Extending life expectancy is one of the major causes for increasing cancer incidence rate. Morbidity in 30-year old patients is $4 / 100000$, while in 80-year ones it reaches up to $120 / 100000$. The most affected group of rectal cancer (RC) is 
aged between 50 and 70 years. The main criterion for evaluating the results after surgical treatment is five-year survival rate. For the patients in I and II clinical stage it is about $60-80 \%$. Liver metastasis (synchronous in $35 \%$ and metachronous in $25 \%$ of the cases) remains a hardly surmountable diagnostic and therapeutic problem in RC. In our own series, $\mathrm{RC}$ incidence rate is highest in the 6th and 7 th decade of patient's life. Endoscopy has turned into the golden standard for CRC diagnosis. In some cases it is the method of choice in the treatment of the disease, too. The examination is applicable in $75-85 \%$ of all the patients as patient's selection and specialist's experience influence upon these numbers. The results from the histopathological examination of the materials obtained during the endoscopic biopsy match those from the post-operative morphological evaluation in $78-84 \%$ of the cases.

Our own results from the routine application of endoscopic techniques with narrow band imaging (NBI) mode colonoscopy show a higher rate of detection of premalignant and early forms of CRC when compared with studies applying conventional colonoscopy only. Various clinical trials evaluate the importance of NBI with or without magnification in order to improve the diagnostic value of colonoscopy $(2,5,8,11)$. Some of them demonstrate an advantage of the method in terms of early diagnosis of adenocarcinoma $(5,11)$. According to other authors, this method can accurately predict histological diagnosis in approximately $90 \%$ of hyperplastic polyps and adenomas $(2,8)$, however, it cannot be recommended for routine application in the clinical practice yet $(5,11)$.

NBI colonoscopy gives better chance for differentiation of the non-adenomatous from the adenomatous polyps of the colon sized less than one mm, as well as of the polyps with lowgrade dysplasia from those with a high-grade one and early cancer $(2,5,8,11-13)$. NBI colonoscopy demonstrates comparable sensitivity (100\%) and specificity (75\%) with chromoendoscopy concerning the differentiation between neoplastic and non-neoplastic polyps. The results are better in comparison to standard colonoscopy (12). In regard of diagnopsis of small polyps both methods show equal sensitivity, specificity and accuracy $(2,5)$. NBI colonoscopy increases the chance of finding the new additional adenomas in case of hereditary nonpolypous colon cancer (CC) (12) and the number of diagnosed adenomas by two times. Its application in risk groups for RC is advisory, especially for sessile adenomas (9).

\section{MATERIAL AND METHODS}

We examined the patients hospitalized in the First Clinic of Surgery, St. Marina University Hospital of Varna, for a period from 2010 to 2012. In such a set of objectives and tasks based on long experience in the Clinic of Surgery in terms of miniinvasive methods of RC treatment in a division with advanced miniinvasive endoscopic surgery, we decided to study the prospective group of patients with precancerous lesions and early CRC for a period from 2010 to 2012. During this period, 652 patients with symptoms of intestinal discomfort, changes in defecation rhythm, rectorhagia and hematohesia, asthenia, and anemia-adynamic syndrome were examined. All the patients included in our prospective study were treated according to a newly-implemented algorithm for early detection, accurate staging and radical treatment of precancerous and early forms of RC.

In 170 patients, 196 lesions of the colon and rectum were found out. In the present study, 163 patients suitable for total colonoscopy to the caecum and thus meeting the inclusion criteria were covered. They presented with a total of 184 newly-diagnosed lesions.

\section{RESULTS}

The results of our study demonstrated that NBI colonoscopy with magnifying endoscopy had the potential to detect more lesions remaining not identified by conventional endoscopy. The relative share of newly-increased mucosal changes increased by 1,9 times (52\%). The newly-diagnosed lesions were mostly small sized. We diagnosed by 2,7 times more lesions sized less than one $\mathrm{mm}$ as well as by two times, 1,7 and 1,3 times more lesions sized 1-3 $\mathrm{mm}, 3-5 \mathrm{~mm}$ and 5-9 $\mathrm{mm}$, respectively. The method did not establish any new formations larger than one $\mathrm{cm}$ or more. The main part of the newly-detected lesions presented with non-specific inflammatory changes, i. e. by 9,2 times more often when compared to conventional endoscopy and represented hyperplastic/inflammatory polyps by 2-3 times more 
Anton Tonev, Nikola Kolev, Valentin Ignatov et al.

often. In four new lesions there were either an early cancer, or areas of high-grade dysplasia while in 12 ones there was a low-grade dysplasia.

NBI colonoscopy increased the visual field which allowed preoperative assessment of invasion depth of CC, i. e. to distinguish invasive from noninvasive $\mathrm{CC}$ without further staining. The diagnostic accuracy was of $87,7 \%$ for the differentiation of pM or pSM1 from pSM2-3 being similar to that of magnification chromoendoscopy (87\%) $(1,9,10)$. Thus, endoscopic CC removal was indicated in case of III-A changes of the capillary network, while lesions classified as type III-B were more likely to have deep infiltration of colon mucosa $(1,9,10)$.

Magnified NBI colonoscopy is a reliable method for diagnosing the small colonic neoplasms, especially those under five $\mathrm{mm}$ in size, for differentiating the non-adenomatous from adenomatous polyps of the colon as well as the polyps with low grade dysplasia from those with high grade one and carcinoma in situ. In addition, it allows mucous carcinoma to be separated from a carcinoma invading the submucous layer. We used the Paris classification for a better staging and classification of recently detected lesions of the colon and rectum.

There is an obvious advantage of NBI colonoscopy over conventional colonoscopy (Table 1).

Table 1. Application of conventional and NBI-colonoscopy for diagnosis of colorectal lesions

\begin{tabular}{|c|c|c|}
\hline $\begin{array}{l}\text { Methods for recently } \\
\text { diagnosed lesions }\end{array}$ & $\mathrm{n}$ & $\%$ \\
\hline conventional colonoscopy & 147 & 79,89 \\
\hline NBI colonoscopy & 180 & 97,83 \\
\hline $\begin{array}{l}\text { total recently diagnosed } \\
\text { lesions }\end{array}$ & 184 & 100,00 \\
\hline
\end{tabular}

Flat and concaved lesions prevail in our contingent (Table 2). Because of unsatisfactory colon preparation, NBI colonoscopy has failed to identify three lesions $(1,63 \%)$ in three patients which have been detected by conventional colonoscopy.

It is evident that routine NBI-regime usage significantly increases the rate of detection of recent
Table 2. Distribution of diagnosed lesions according to their type and methods of examination

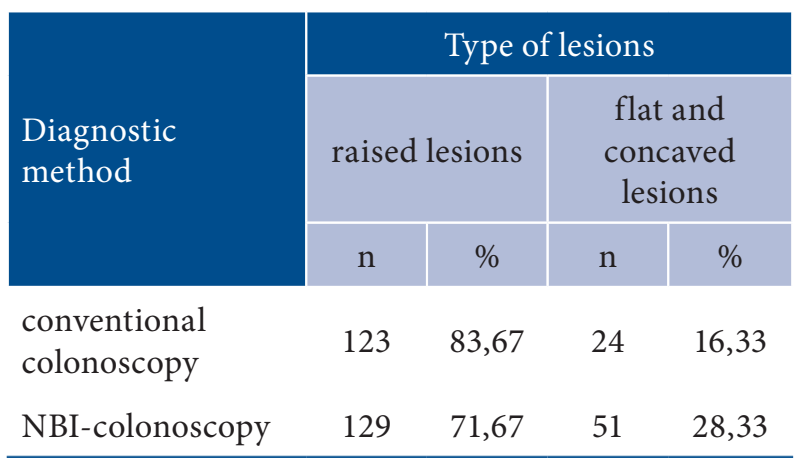

Table 3. Distribution of recently diagnosed superficial lesions according to Paris classification

\begin{tabular}{|c|c|c|}
\hline \multirow[t]{2}{*}{ Lesion type } & \multicolumn{2}{|c|}{$\begin{array}{l}\text { Number and percentage of lesions } \\
\qquad(\mathrm{n}=96)\end{array}$} \\
\hline & $\mathrm{n}$ & $\%$ \\
\hline Type 0-I & 42 & 43,75 \\
\hline (0-Ip) & 27 & 28,12 \\
\hline (0-Is) & 15 & 15,63 \\
\hline Type 0-II & 31 & 32,29 \\
\hline (0-IIa) & 11 & 11,46 \\
\hline (0-IIb) & 8 & 8,33 \\
\hline$(0-\mathrm{IIC})$ & 12 & 12,50 \\
\hline Type 0-III & 23 & 23,96 \\
\hline
\end{tabular}

\section{Excellent $\quad$ Good $\square$ Poor}

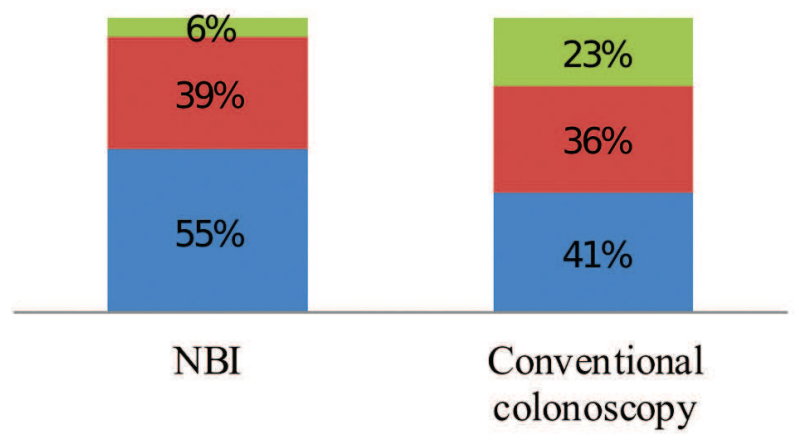

Fig 1. Visualization of flat lesions by conventional and NBI colonoscopy 
Table 4. Time duration of conventional and NBI colonoscopy

\begin{tabular}{l|c|c}
\multirow{2}{*}{\begin{tabular}{l} 
Diagnostic method \\
\cline { 2 - 3 }
\end{tabular}} & \multicolumn{2}{|c}{ Time duration (min) } \\
\cline { 2 - 3 } $\begin{array}{l}\text { conventional } \\
\text { colonoscopy }\end{array}$ & 11,28 & $\begin{array}{c}\text { mean-time } \\
\text { difference }\end{array}$ \\
NBI-colonoscopy & 13,48 & 4,01 \\
\hline
\end{tabular}

flat lesions of the colon and rectum, which would have otherwise been missed by routine colonoscopy.

On Table 4 it can be seen that the difference of time duration between both methods of $2 \mathrm{~min}$ and $20 \mathrm{sec}$ or of $17 \%$ is not significant.

Excellent and satisfactory visualization of the lesions was achieved in $77 \%$ of the cases in the conventional group and in $94 \%$ in the NBI-assisted one (Fig. 1).

\section{DISCUSSION}

Early RC detection and diagnosis are the key strategies for decreasing the recurrence rate and increasing patient's survival. Endoscopy has turned into the golden standard for RC diagnosis. In some cases it is the method of choice in the treatment of the disease, too. The examination is applicable in $75-85 \%$ of all the patients where their selection and specialist's experience influence on these numbers. The results from the histopathological examination of the materials obtained during the endoscopic biopsy match those from the post-operative morphological evaluation in $78-84 \%$ of the cases.

Due to the routine use of endoscopic methods with NBI-assisted regimes in our study, detection of premalignant and early CRC is comparatively higher than in studies using conventional endoscopy. Different clinical studies evaluate the role of NBI with or without magnification to improve the diagnostic value of colonoscopy $(5,9,10,12)$. Some of them show advantages of this method regarding the diagnosis of early adenocarcinoma. According to other authors, this method can predict the exact histological diagnosis in approximately $90 \%$ for the hyperplastic polyps and adenomas $(1,6,10)$, however, it is not recommended for routine clinical use yet $(4,12)$.
The results from our study show that NBI with magnifying endoscopy gives the opportunity to diagnose lesions not established via conventional endoscopy. The rate of the newly-detected superficial changes increased by 1,9 times or by $52 \%$. They were of comparatively smaller size. Thus we diagnosed by 2,7 times more lesions sized less than one $\mathrm{mm}$ as well as by two times, 1,7 and 1,3 times more lesions sized 1-3 mm, 3-5 $\mathrm{mm}$ and 5-9 $\mathrm{mm}$, respectively. The method did not establish any new formations larger than one $\mathrm{cm}$ or more. The main part of the newly-detected lesions presented with non-specific inflammatory changes, i. e. by 9,2 times more often when compared to conventional endoscopy and represented hyperplastic/inflammatory polyps by 2-3 times more often. In four new lesions there were either an early cancer, or areas of high-grade dysplasia while in 12 ones there was a low-grade dysplasia.

NBI increases the rate of differentiation between non-adenomatous and adenomatous polyps of the colon of less than one $\mathrm{mm}$ in size as well as between polyps with low-grade dysplasia and those with high-grade one and early carcinoma $(7,8,13)$. NBI demonstrates a similar sensitivity (100\%) and specificity (75\%) to chromoendoscopy when differentiating between neoplastic and nonneoplastic lesions being better than standard colonoscopy. Concerning the diagnosis of small polyps, both methods show one and the same sensitivity, specificity and accuracy $(2,5)$. NBI increases the chance of detection of additional adenomas in patients with hereditary non-polypous CC (3). The number of adenomas that are identified by NBI colonoscopy increases twofold. The application of this method is recommended in risk groups for RC and for diagnosis of flat adenomas (6).

Our own and other authors' results confirm the clinical significance of the higher accuracy and lower percentage of false-positive or negative results $(5,7,9,10)$.

Endoscopic removal of colonic tumours is indicated in III-A changes in the capillary network while lesions classified as type III-B most often infiltrate the lining of the colon in depth $(1,9,10)$.

\section{CONCLUSION}

NBI colonoscopy with magnifying endoscopy represents a reliable method for the diagnosis of small 
Anton Tonev, Nikola Kolev, Valentin Ignatov et al.

neoplasms of the colon and, especially, of those less than five $\mathrm{mm}$ in size, for the differentiation of nonadenomatous from adenomatous polyps as well as of polyps with high-grade dysplasia from those with low-grade one. In addition, it can help differentiating the mucous cancer from the cancer invading the submucous layer.

\section{REFERENCES}

1. Adams, D. R., G. J. Blatchford, K. M. Lin, C. A. Ternent, A. G. Thorson, M. A. Christensen. Use of preoperative ultrasound staging for treatment of rectal cancer.- Dis. Colon Rectum, 42, 1999, No 2, 159-166.

2. Akahoshi, K., T. Misawa, H. Fujishima, Y. Chijiiwa, H. Nawata. Regional lymph node metastasis in gastric cancer: evaluation with endoscopic US.Radiology, 182, 1992, No 2, 559-564.

3. Akahoshi, K., Y. Chijiiwa, I. Sasaki, S. Hamada, Y. Iwakiri, H. Nawata, et al. Pre-operative TN staging of gastric cancer using a $15 \mathrm{MHz}$ ultrasound miniprobe.- Br. J. Radiol., 70, 1997, No 835.

4. Akahoshi, K., Y. Chijiiwa, S. Hamada, I. Sasaki, H. Nawata, T. Kabemura, et al. Pretreatment staging of endoscopically early gastric cancer with a 15 $\mathrm{MHz}$ ultrasound catheter probe.- Gastrointest. Endosc., 48, 1998, No 5, 470-476.

5. Glaser, F., P. Schlag, C. H. Herfarth. Endorectal ultrasonograhy for the assessment of invasion of rectal tumours and lymph node involvement.- $B r$. J. Surg., 77, 1990, No 8, 883-887.

6. Hamada, S., K. Akahoshi, Y. Chijiiwa, I. Sasaki, H. Nawata. Preoperative staging of colorectal cancer by a $15 \mathrm{MHz}$ ultrasound miniprobe.- Surgery, 123, 1998, No 3, 264-269.

7. Heinz, A., P. Mildenberger, M. Georg, S. Braunstein, T. Junginger. Endoscopic ultrasonography in the diagnosis of regional lymph nodes in esophageal and gastric cancer - results of an in-vitro study.- Endoscopy, 25, 1993, No 3, 231-235.
8. Hünerbein, M., S. Totkas, B. M. Ghadimi, P. M. Schlag. Preoperative evaluation of colorectal neoplasms by colonoscopic miniprobe ultrasonography.- Ann. Surg., 232, 2000, No 1, 46-50.

9. Massari, M., U. Cioffi, L. Rosso, M. Chiarelli, F. Gabrielli. Value and limits of endorectal ultrasonography for preoperative staging of rectal carcinoma.- Surg. Laparosc. Endosc., 8, 1998, No 6, 438-444.

10. Nishimori, H., K. Sasaki, K. Hirata, H. Natori. The value of endoscopic ultrasonography in preoperative evaluation of rectal cancer.- Int. Surg., 83, 1998, No 2, 157-160.

11. Rifkin, M. D., S. M. Ehrlich, G. Marks. Staging of rectal carcinoma: prospective comparison of endorectal US and CT.- Radiology, 170, 1989, No 2, 319-322.

12. Shimizu, S., M. Tada, K. Kawai. Use of endoscopic ultrasonography for the diagnosis of colorectal tumors.- Endoscopy, 22, 1990, No 1, 31-34.

13. Zaheer, S., J. H. Pemberton, R. Farouk, R. R. Dozois, B. G. Wolff, D. Iistrup. Surgical treatment of adenocarcinoma of the rectum.- Ann. Surg., 227, 1998, No 6, 800-811.

14. Thrall, M. J., S. E. Pambuccian, E. B. Stelow, D. M. McKeon, L. Miller, K. Savik, et al. Impact of the more restrictive definition of atypical squamous cells introduced by the 2001 Bethesda System on the sensitivity and specificity of the Papanicolaou test: a 5-year follow-up study of Papanicolaou tests originally interpreted as ASCUS, reclassified according to Bethesda 2001 criteria.- Cancer, 114, 2008, No 3, 171-179. 